\title{
Employer Accommodation and Labor Supply of Disabled Workers*
}

\author{
Matthew J. Hill \\ University of Pompeu Fabra \\ and RAND
}

\author{
Nicole Maestas \\ RAND
}

October 2014

\author{
Kathleen J. Mullen \\ RAND and IZA
}

\begin{abstract}
We use longitudinal data from the Health and Retirement Study to examine what factors influence employer accommodation of newly disabled workers and how effective such accommodations are in retaining workers and discouraging disability insurance applications. We find that only a quarter of newly disabled older workers are accommodated by their employers in some way following onset of a disability. Importantly, we find that few employer characteristics explain which workers are accommodated; rather, employee characteristics, particularly the presence of certain personality traits correlated with assertiveness and open communication, are highly predictive of accommodation. This suggests that policies targeting employer incentives may not be particularly effective at increasing accommodation rates since employers may not even be aware of their employees' need for accommodation. We also find that if employer accommodation rates can be increased, disabled workers would be significantly more likely to delay labor force exit, at least for two years. However, we do not find significant effects on the disability insurance claiming margin.
\end{abstract}

\footnotetext{
${ }^{*}$ We thank Sarah Kups for research assistance and Orla Hayden for programming assistance. We also thank Susanne Bruyere, Katherine Carman, Erik Meier, Sarah von Schrader and RAND brownbag participants for helpful comments and suggestions. This research was supported by a grant from the Alfred P. Sloan Foundation.
} 


\section{Introduction}

The disability insurance system in the U.S. is currently in crisis. Over the past few decades the number of Social Security Disability Insurance (SSDI) beneficiaries has increased dramatically and, moreover, their composition has shifted towards younger beneficiaries and those with higher cost health impairments, leading to longer, costlier durations on the rolls (Autor and Duggan, 2006). Because of these trends the Federal Disability Insurance Trust Fund is projected to exhaust its assets by 2016 (Board of Trustees, 2013). Strong SSDI work disincentives and recent evidence on skill depreciation even during the application period suggest that effective reforms aimed at discouraging dependence on disability insurance benefits should focus on intervening before disabled workers quit their jobs in order to apply for benefits (Autor, Maestas, Mullen and Strand, 2011). Indeed, a number of recent influential proposals focus on ways to incentivize employers to retain employees after they experience the onset of a disability (Autor and Duggan, 2010; Burkhauser and Daly, 2011; see also Leibman and Smalligan, 2013).

A natural way for employers to retain disabled workers is to accommodate their disabilities so they can continue to be productive despite the existence of a health impairment that would otherwise impede work, for example by modifying job requirements or work schedules. However, the process through which employers learn about and accommodate employees’ disabilities is not well understood. Understanding how employees are accommodated or not following disability onset is important not only for designing policies to increase accommodation rates, which despite the Americans with Disabilities Act (ADA) remain shockingly low, but also for evaluating the effectiveness of employer accommodation in 
retaining disabled workers and discouraging them from applying for SSDI benefits. ${ }^{1}$ In this paper we use longitudinal data on newly disabled workers from the Health and Retirement Study (HRS) to provide new evidence on what factors determine accommodation of newly disabled workers, as well as the short- and long-term effects of employer accommodation on employment and SSDI claiming behavior.

Despite the focus on employers in the policy debate, the evidence base supporting the effectiveness of reforms aimed at changing employer behavior is limited. Few papers have studied what factors influence employer accommodation of disability and for the most part focus on the impact of anti-discrimination legislation (e.g., Charles, 2005; Burkhauser, Schmeiser and Weathers, 2012). ${ }^{2}$ Papers examining how various forms of employment support affect the employment trajectory following disability onset are also limited and mostly concentrated in the pre-ADA era (i.e., prior to 1992-1994; see Burkhauser, Butler and Kim, 1995; Daly and Bound, 1995; Burkhauser, Butler, Kim and Weathers, 1999) or other countries (e.g., Canada (Campolieti, 2005) or Denmark (Høgelund and Holm, 2014)).

Even though the ADA mandates that employers provide "reasonable" accommodation of disabled workers except in cases of "undue hardship," we find that only slightly more than a quarter of newly disabled workers report that their employer did anything special to help them out so that they could stay at work after they became disabled. ${ }^{3}$ Yet, a 1998 survey of private

\footnotetext{
${ }^{1}$ If sicker employees tend to self-sort into jobs with accommodating employers, or if employers tend to accommodate only the "best prospects" in terms of employee retention, then a simple comparison of the work outcomes of accommodated vs. non-accommodated workers will yield biased estimates (although the direction of the bias is not clear).

${ }^{2}$ A recent study by Bronchetti and McInerney (forthcoming) examines employer accommodation of the subset of disabled workers who were injured on the job specifically, with an emphasis on the role of Workers' Compensation.

${ }^{3}$ The legal literature suggests that the main reason the ADA has been ineffective at encouraging employer accommodation is that the courts have applied a much stricter definition of what is a covered disability than that intended by Congress (see, e.g., Race and Dornier, 2009). The 2008 amendments to the ADA were intended to correct this misinterpretation and specifically widen the definition of covered disability. We are unaware of any
} 
sector human resource managers found that reports of accommodation from the employer side were widespread, including restructuring jobs or modifying work hours (69 percent), acquiring or modifying equipment or devices (59 percent), making parking or transportation accommodations (67 percent) and modifying the work environment (62 percent) (Bruyere, 2000). In the same survey, 72 percent of employers report that they have a formal dispute/grievance process for accommodations, and 79 percent report having a formal (45 percent) or informal (34 percent) return to work or disability management program.

Since many more employers report accommodating at least one disabled worker than employees report being accommodated, it is unlikely that newly disabled workers are concentrated in jobs with accommodating employers. Indeed we find no evidence that workers who expect to become disabled are any more likely to be employed by firms that could be perceived as more flexible or accommodating (e.g., firms providing long term disability coverage, or those that would allow one to reduce hours if needed). Thus, it seems likely that there is something about the accommodation process that leads employers to accommodate fewer employees than they could.

One possible explanation for the discrepancy in reports is that employers selectively accommodate employees who are more valuable to them (i.e., more likely to continue working if accommodated). We investigate this possibility by relating a rich set of employee, job and employer characteristics to the probability of receiving accommodation. We find little evidence that the employee's health, type or severity of disability is associated with employer accommodation. Similarly, employers are not any more likely to accommodate workers with better prior labor force attachment, although they are more likely to accommodate workers with

empirical papers on the effectiveness of the 2008 amendments, however our data shows no increase in accommodation rates all else equal after 2008. 
sufficient tenure at the firm. Characteristics of the employers themselves (offering LTDI, etc.) are also uncorrelated with accommodation rates. Rather, the most predictive factors are employee characteristics such as education and race.

This suggests a second possible explanation—that employees are the source of the roadblock in the accommodation process. Accommodation is a multi-stage process, whereby an employee must first request accommodation and the employer may respond accordingly. Even though the ADA mandates reasonable accommodation of disabilities in the workplace, employees may not know this or may still fear retribution from their employer if they make such a request (von Schrader et al., 2013). A May 2012 supplement to the Current Population Survey (CPS) found that only 12.5 of disabled workers (as defined by the CPS) ${ }^{4}$ reported that they requested a change in their current workplace (Bureau of Labor Statistics, 2013). In some cases, the employer may not wish to provide the accommodation requested by the employee and the employer and employee may iterate to come to a mutually agreeable solution. This may require persistence on the part of the employee.

Because the HRS does not contain questions on whether the employee asked for accommodation (merely whether he received it), we cannot investigate this directly in our data. However, starting in 2006 the HRS administered a psychosocial leave-behind questionnaire to a random half of respondents in alternating years. Thus, we are able to investigate the influence of a number of personality traits, including the "Big Five" traits of openness, conscientiousness, extraversion, agreeableness and neuroticism, and two measures of sense of control, personal mastery and perceived constraints. We find that agreeableness and neuroticism are both strongly negatively correlated with receiving accommodation, whereas extraversion is positively

\footnotetext{
${ }^{4}$ See Burkhauser et al. (2012) for a discussion of how the CPS definition of disability relates to individual reports of work-limiting health impairments.
} 
correlated with accommodation. These personality traits are positively associated with demanding and negatively associated with avoiding conflict management styles (Antonioni, 1998). Individuals with demanding styles are often aggressive and make sure that their needs are met; individuals with avoiding styles do not tend to communicate their needs. We also find that individuals who score high on the perceived constraints measure of sense of control—that is, they are reliant on others for solving problems—are more likely to receive accommodation.

Finally, we turn our attention to estimating the causal effects of employer accommodation on employee outcomes such as employment and SSDI application and receipt. Because we do not find evidence that accommodation is systematically offered to employees with high unobserved preferences for work, we conclude that ordinary least squares regressions of work outcomes on accommodation will not lead to biased estimates. We also reweight observations using the propensity score in order to allow for a more flexible specification. We find similar results when weighting vs. not weighting. We find that accommodation substantially and significantly increases the probability of continued employment in the two years following disability onset; a worker receiving accommodation is 17 percentage points (40 percent) more likely to work in the next survey wave than a worker who did not receive accommodation. However, this effect almost completely vanishes by the next survey wave (up to four years after onset). Although any accommodation is effective, we find that accommodations involving work changes (e.g., job restructuring, helping an employee learn new skills) are most effective. However, we do not find any evidence that accommodation reduces SSDI application or receipt, suggesting that individuals on the margin of working vs. dropping out of the labor force depending on whether their disability is accommodated are not also on the margin of applying for disability insurance. 
Our findings have a number of important implications for disability employment policy. First, if disabled employees are not disclosing their need for accommodation to employers, then this suggests policies targeting employer incentives for retaining disabled workers—e.g., by mandating private disability insurance—-may not be particularly effective at increasing accommodation rates. Unlike other experience-rated programs like Workers' Compensation, there is no built-in reporting system for disabling injuries that occur off the job, and the lack of visible impairment in many cases means that employers are often unaware that an employee suffers from a work-limiting disability. ${ }^{5}$ Rather, our findings suggest that policies targeting the environment surrounding disability disclosure may be more effective at increasing accommodation of disabled employees. For example, a new rule requiring federal contractors to demonstrate that at least 7 percent of their employees are disabled (or that they are taking steps to achieve that target) could increase accommodation rates among federal contractors not only because employers will now explicitly ask their employees if they have a disability but also because employees may now perceive that being disabled is actually desirable to their employer (Weber, 2014). If employer accommodation rates increase, we find that disabled workers would be more likely to delay labor force exit, at least for two years. However, increasing employer accommodation is unlikely to stem the tide of new SSDI beneficiaries.

\section{Data and Descriptive Statistics}

We use data from the nationally representative Health and Retirement Study (HRS), which has surveyed individuals ages 51 and older every two years since 1992. We use data through the 2010 survey wave. We identify individuals as disabled if they answer yes to the

\footnotetext{
${ }^{5}$ This likely accounts for the differences between our findings and those of Bronchetti and McInerney (forthcoming), who find that employer characteristics matter most in determining whether an employee who is injured on the job receives accommodation.
} 
question, "Do you have any impairment or health problem that limits the kind or amount of paid work you can do?” We restrict our attention to newly disabled workers whose disability onset is observed in panel, that is, those individuals who are not disabled when they enter the panel but who report a work disability sometime thereafter while they are (still) employed. This allows us to condition on a rich set of job and employer characteristics before the onset of the disability, so that we can examine their influence on whether the individual's disability is accommodated by his employer and whether he continues to work or claims disability insurance after becoming disabled.

Table 1 lists the restrictions we use in constructing our sample and the sample size after each restriction. Of the 15,906 respondents who enter the panel without reporting a work disability, 3,144 or 20 percent report a work-limiting health condition at some time in the future while still in working-age years (that is, before they become eligible to claim full Social Security benefits at age 65). We further restrict the sample to individuals who are employed at the time of disability onset, that is, they answer yes to the question, "Were you employed at the time your health began to limit your ability to work?” Note that, prior to 1998, the survey included a skip pattern in which this question was only asked of individuals who reported that the impairment or health problem first began to "bother" them after the last wave's interview. This resulted in the exclusion of a large number of individuals (28 percent) since 59 percent of newly disabled respondents report that the health problem causing their disability first began to bother them more than two years ago. ${ }^{6}$ Starting in 1998, employment status at onset was asked of all disabled

\footnotetext{
${ }^{6}$ Respondents were also asked when their health problem first began to "interfere with [their] work.” A sizeable fraction (42 percent) still reported onsets occurring more than two years ago, even though two years ago in the last survey wave they reported that their health did not limit their ability to work. We include these respondents in our main analyses, but perform robustness checks where we exclude them.
} 
respondents. Of those who were posed the question, 73 percent report working at the time their health first began to limit their ability work.

Next, the respondents were asked, "At the time your health started to limit your ability to work, did your employer do anything special to help you out so that you could stay at work?” Possible responses were yes, no, "left immediately,” "self-employed” and (starting in 1998) “no help needed.” We excluded all responses other than yes or no. We further limit the sample to those who were observed in the wave prior to onset and those with no missing key covariates, resulting in 1,164 newly disabled older workers. ${ }^{7}$ Finally, for specifications that examine the influence of job and employer characteristics that were collected only in the prior wave, we limit the sample to the 972 newly disabled respondents (16 percent) who were also working in the prior wave.

Table 2 presents summary statistics for the main sample of 1,164 respondents, overall and by accommodation status. In our sample only 26 percent of newly disabled older workers receive some form of employer accommodation upon becoming disabled, despite the fact that by construction all onsets occurred after 1992, when the ADA was implemented. If the respondent reported that their employer did something special to help them out, they were then asked more detailed questions about what types of things the employer did. We grouped their responses into three different dimensions of accommodation (not mutually exclusive): changes to time (allowing more breaks, allowing different arrival or departure times or shortening the work day), reported by 55 percent of accommodated respondents; provision of equipment/assistance (getting someone to help, getting special equipment, arranging special transportation), reported by 48 percent of accommodated respondents; and changes to work (changing the job, helping to learn

\footnotetext{
${ }^{7}$ For some covariates with large numbers of missing values (e.g., number of employees at the respondent's firm), we included a missing indicator instead of dropping the observation.
} 
new job skills), reported by 37 percent of respondents. Twenty-two percent of accommodated respondents reported that they received some other accommodation than one of the eight types prompted by HRS. See Table A1 for a more detailed breakdown of the types of accommodation. Intriguingly, with the exception of only a few characteristics (age, race and earnings), individuals whose employers accommodate their disabilities are not very different from those whose employers do not accommodate their disabilities. While older and higher earning workers are slightly more likely to be accommodated, there is no evidence that healthier workers or workers with certain kinds of disabling conditions or job types are more or less likely to be accommodated. Employer characteristics also do not seem to be associated with whether an employee receives any accommodation. However, it is evident that employees who are accommodated are significantly more likely to continue to work following disability onset and less likely to apply for and receive disability insurance. Overall, fewer than half of disabled workers are still working 2-4 years after onset. One-third have applied for disability insurance benefits and of those two-thirds eventually receive benefits. Note that a large fraction of individuals are neither working nor applying for or receiving disability insurance benefits (22 and 33 percent, respectively).

Finally, in 2006 the HRS began administering a psychosocial leave-behind questionnaire (LBQ) to a random half of respondents in alternating years. The module contains questions enabling one to construct measures of the "Big Five” personality traits—openness, conscientiousness, extraversion, agreeableness and neuroticism—on a 1-4 scale, with higher values corresponding to stronger presence of a given personality trait. We also constructed two measures of sense of control: personal mastery and perceived constraints. The personal mastery index measures how much a person believes they can affect change, containing items such as "I 
can do the things I want to do," "What happens depends on me,” and "When I want to do something I find a way to succeed at it.” The perceived constraints measures, in contrast, measures the extent to which outside factors control an individual's life and contains items such as "I feel helpless in dealing with the problems of life," "I have little control over the things that happen to me,” and “Other people determine what I can and cannot do.” The control measures average over items rated on a 1-6 scale with 6 corresponding to strongly agreeing with a statement and 1 to strongly disagreeing. Thus, higher scores of personal mastery and lower scores of perceived constraints correspond to a higher sense of control. For analyses using the personality measures, we restrict the sample to the 115 HRS respondents who completed the psychosocial questionnaire prior to onset of disability in a later wave. ${ }^{8}$ Table A2 reports means, standard deviations and correlations between the personality and control measures.

\section{Empirical Methods}

We are interesting in answering two questions. First, what factors determine whether a newly disabled worker's employer accommodates his disability? And second, what is the causal effect of such accommodation on the probability that the employee continues to work despite the onset of a work-limiting health condition? Our approach to the second question depends on the answer to the first question, specifically on whether we find evidence consistent with the existence of unobserved factors that are correlated with both employer accommodation and propensity to work (i.e., prior labor force attachment or disability severity).

Since we do not find evidence of that unobserved “confounders” exist in our setting, we propose two methods for estimating the causal effect of employer accommodation on labor

\footnotetext{
8 This limits the sample to onsets that occurred in 2008 (in the half of the sample receiving the LBQ in 2006) or 2010 (with personality measures taken from 2006 or 2008).
} 
supply that rely on the well-known conditional independence assumption (CIA): ordinary least squares (OLS) and propensity score reweighting. The CIA simply states that, conditional on a set of observable characteristics, labor supply is independent of assignment of accommodation. While the CIA is not fundamentally a testable assumption, we show in the next section that employers do not seem provide accommodation selectively to individuals with higher labor force attachment in general or less severe disabilities, as may be expected. Rather, employer accommodation seems driven primarily by features of the employee's personality correlated with seeking out and obtaining help.

Although both OLS and propensity score methods rely on the same conditional independence assumption, OLS imposes additional functional form assumptions that propensity score methods do not rely on. Propensity score reweighting uses the propensity score to reweight the distribution of covariates $X$ in the control group to match the distribution of $X$ observed in the treated group. Intuitively, it places more weight on untreated observations that "look like" treated observations and down-weights untreated observations that do not so that the two groups are more directly comparable. Thus, one can use the reweighted control group to estimate the counterfactual distribution of the outcome $Y$ for the treated group if they had never been treated.

We implement propensity reweighting as follows. First, we estimate the propensity score function $p\left(X_{i}\right)$ using a probit regression of employer accommodation (treatment) on individual, job and employer characteristics $X_{i}$ measured in the wave prior to onset. We also include indicators for the disabling condition (e.g., musculoskeletal, emotional) which is also predetermined. We then construct the following estimator for the average treatment effect on the treated (ATET): 


$$
\Delta^{\text {ATET }}=\frac{1}{N^{T}} \sum_{i=1}^{N^{T}+N^{C}}\left(D_{i} Y_{i}-\left(1-D_{i}\right) \frac{p\left(X_{i}\right)}{1-p\left(X_{i}\right)} Y_{i}\right),
$$

where $D_{i}=1$ if individual $i$ was accommodated (treated) and $D_{i}=0$ otherwise, $N^{T}$ is the number of treated individuals and $N^{C}$ the number of control individuals, and $Y_{i}$ is the outcome of interest (e.g., working after onset). This estimator has been shown to be a consistent estimator of ATET (Dehejia and Wahba, 1999; DiNardi, Fortin and Lemieux, 1996). Finally, we consider the robustness of our ATET estimate to use of other propensity score methods such as radius, nearest neighbor and block matching (Imbens, 2014).

\section{Determinants of Employer Accommodation}

In this section we explore which factors are correlated with employer accommodation following disability onset. Understanding what factors determine which employees are accommodated is important not only for assessing the scope of increasing accommodation rates in the U.S. through different policy levers but it is also a necessary prerequisite for estimating the causal effect of employer accommodation on employee outcomes, particularly labor supply. We examine determinants of employer accommodation in three ways. First, we examine whether employees who are likely to become disabled self-sort into jobs with employers who they could reasonably expect to be accommodating in the event that they become disabled. Second, we examine which individual, job and employer characteristics are associated with employer accommodation of workers following disability onset. Finally, using a unique subsample of HRS respondents completing a psychosocial leave-behind questionnaire we examine whether individuals with certain personality attributes are more or less likely to be accommodated following disability onset. 


\subsection{Role of Self-Sorting}

To examine whether employees with health problems are more likely to sort into jobs with more accommodating employers, we use a sample of healthy respondents (before they became disabled, if they ever did) in the first wave of employment with a given employer. We use three measures of whether an employer may be perceived by employees as more accommodating to individuals with disabilities: whether the employer offers long-term disability insurance (LTDI), whether the employer would let older workers move to a less demanding job with less pay if they wanted to, and whether the employer would allow the individual to reduce the hours in his regular working schedule if he wanted to. Table 3 presents the mean and standard deviation of individuals’ self-reported probability of becoming disabled in the next 10 years by each of the three employer characteristics. The difference in individuals' expectations about becoming disabled is statistically different from zero only for individuals whose employers differ on the offer of LTDI, and only before controlling for other covariates. Yet, employees of firms offering LTDI believe themselves less likely to become disabled than employees of firms not offering LTDI. Thus, we do not find any evidence that those individuals with health problems pre-sort into employers who would be more likely to accommodate them in the event that they become disabled.

\subsection{Role of Individual, Job and Employer Characteristics}

Next we try to determine which factors are associated with employer accommodation of individuals’ actual disabilities. Table 4 presents estimates of marginal effects from a probit model of any employer accommodation. All predictor variables are measured in the wave before the respondent first reports a work-limiting disability. Column 1 presents estimates of the effects 
of individual demographic and health characteristics on accommodation for the sample of 1,164 newly disabled respondents who were employed at the time their health began to limit their work but not necessarily in the wave prior. Column 2 restricts the sample to the 972 respondents (83.5 percent) who were both employed at onset and two years earlier and adds job and employer characteristics measured in the prior wave to the regression. Note that, even though individuals who were not working two years earlier are less likely to be accommodated than those who were working, the estimated effects on the regressors in common are similar in size and statistical significance across the two groups. ${ }^{9}$ Finally, columns 3-5 estimate the effects of factors on each of three dimensions of accommodation: time, equipment/assistance and work change. We omit “other" unspecified accommodations. See Section 2 for the grouping of types of accommodation into dimensions.

Consistent with the summary statistics, we find that education and race are the strongest predictors of accommodation. Workers with at least some college are 8-12 percentage points (3045 percent) more likely to be accommodated than those without a high school degree. Women and minorities are less likely to be accommodated, and non-black minorities (e.g., Asians) are especially unlikely to be accommodated. The finding of race is particularly interesting since, unlike education, it is not related to skill level and therefore should not affect labor demand. Surprisingly, we find little evidence that characteristics of the actual health impairment are predictive of accommodation, with the possible (weak) exception of back problems and allergies. For the most part these conclusions continue to hold when considering different dimensions of accommodation, although college completion appears to be less of a factor for time- and assistance-related accommodations than it does for work change accommodations, and race

\footnotetext{
${ }^{9}$ This is consistent with employers accommodating individuals with higher job tenure or lower labor force attachment. In Table A3 we show that accommodation is not correlated with longer lags of work status, suggesting that job tenure is the operating driver of accommodation, not labor force attachment.
} 
appears not to factor significantly into work change accommodations. Interestingly, we find that overweight workers are more likely to receive work change or assistance-related accommodations compared to their normal weight peers.

Next, we turn to the influence of job and employer characteristics. The fact that newly disabled workers who had not been working in the wave prior to onset are less likely to be accommodated suggests that job tenure may be an important factor in determining employer accommodation. We divide job tenure measured in the prior wave approximately into quintiles. We find that tenure in the middle quintile (6-12 years tenure, two years earlier) is (weakly) correlated with higher rates of employer accommodation, especially for time-related accommodations. There is also some evidence that employees with very long tenure are more likely to receive some sort of time-related accommodation, consistent with the idea that they are phasing into retirement. More physically demanding jobs are somewhat less likely to be accommodated by allowing work changes or providing employees with assistance. ${ }^{10}$ On the other hand, more stressful jobs are more likely to be accommodated with changes in work timing or provision of assistance. There is no evidence that employer characteristics, such as offering LTDI, accommodating older workers or allowing employees in general to reduce their hours, are associated with accommodation. Industry and occupation fixed effects were jointly insignificant as well.

All of our disability onsets occur after the implementation of the ADA, and we find no evidence that accommodation rates increased after the ADA was amended in 2008 (not shown). There is also no evidence that employee size is meaningfully related to employer

\footnotetext{
${ }^{10}$ We also estimated specifications which included interactions between physically demanding jobs and employee health; the interactions were statistically insignificant and did not alter the results.
} 
accommodation. ${ }^{11}$ Unlike Burkhauser, Schmeiser and Weathers (2011), we do not find strong evidence that job-related injuries are significantly more likely to be accommodated than non-jobrelated injuries, although their sample included pre-ADA onsets and they also found that jobrelated injuries were more likely to be accommodated in states that lacked anti-discrimination laws prior to the ADA. ${ }^{12}$

\subsection{Role of Personality}

The results above suggest that it is employee rather than employer characteristics—and perhaps the employee's relationship with the employer-that matters most in determining employer accommodation following onset of a work-limiting health condition. We hypothesize that personality traits correlated with making one’s needs known to employers and seeking out help will be positively correlated with employer accommodation. For example, extraverts are more likely to engage socially and may be more likely to mention their health problem to their employer. By the same token, disagreeable workers may be more willing to complain and endure conflict in an effort to come to a solution with their employer that would satisfy their needs. Moreover, individuals who score high on the perceived constraints measure are less likely to feel that they can solve problems on their own and may be more likely to request help from their employer.

We test these hypotheses by taking advantage of a unique psychosocial leave-behind questionnaire (LBQ) that the HRS began administering in 2006 to a rotating half of its respondents every four years. Because of the late, staggered introduction of the LBQ, we observe

\footnotetext{
${ }^{11}$ The ADA applies to employers with more than 25 regular employees.

${ }^{12}$ We also estimated versions of the model with state fixed effects (on restricted data) and found no significant effects of state of residence on employer accommodation. Again, however, all of our estimates are in the post-ADA era in which all states are subject to antidiscrimination legislation.
} 
only 115 individuals who disability onsets occurred after they completed the LBQ in 2006 or 2008. The psychology literature is mixed on whether personality traits are stable enough over the life course to apply the measures retroactively to capture onsets that occurred prior to completing the LBQ. For example, Costa et al. (2000) and Cobb-Clark and Shurer (2012) find that personality traits are relatively stable, however recent research with larger sample sizes (Specht et al., 2011) and longer time horizons (Billstedt et al., 2014) finds evidence that personality traits change over the life course. In particular, Specht et al. (2011) find that older individuals who go through major life events are the most likely to show changes in personality.

We investigate whether onset of a work-limiting health condition is associated with changes in personality traits by limiting our sample to healthy and newly disabled respondents with personality traits measured four years apart, in 2006 and 2010. Table 5 reports the results of these regressions. Each row represents a separate regression of a personality trait in 2010 on its own lagged measure in 2006 and an indicator for whether the individual experienced a disability onset between the two measurement years, i.e., in 2008 or 2010. If the personality measures are stable and not influenced by the onset of a work-limiting health condition, then the coefficient on the lagged trait should be close to one and the coefficient on disability onset should be zero. Consistent with the prior literature, we find that for the most part personality measures are relatively stable over four years (although statistically distinct from 1). However, we find that newly disabled individuals experience significant personality changes after onset. Specifically, we find that they are slightly less conscientious and extraverted after disability onset, and they are significantly less likely to feel in control of their environment. These results lead us to conclude that personality traits are not stable enough to apply retroactively and we therefore limit 
our analyses of personality traits as determinants of accommodation to the 115 respondents for whom we have pre-onset measures.

Table 6 presents estimates of marginal effects of probit models of employer accommodation on the "Big Five” personality measures_openness, conscientiousness, extraversion, agreeableness and neuroticism—and two measures of sense of control, personal mastery and perceived constraints. Column 1 presents the model estimated on all disabled workers completing the questionnaire, and columns 2-3 presents estimates for the subset of disabled workers who were also working in the wave prior to onset, with and without demographic control variables, for comparison with Table 5.

Despite the very small sample size, the specifications of the model with personality traits have a similar explanatory power to the specifications without personality traits in Table 4. Indeed, pseudo r-squared of the models with personality traits alone are comparable to the rsquared in the models without personality traits ( 0.05 and 0.09 vs. 0.07 and 0.09 , for columns $1-2$ of Tables 4 and 6, respectively). Together, r-squared of the model with personality traits and the full set of controls is 0.35 . We find that the personality traits agreeableness and neuroticism are consistently and strongly negatively correlated with employer accommodation. A standard deviation increase of 0.50 (see Table A2) in agreeableness is associated with an approximately 70 percent decrease in the probability of being accommodated, and a one-standard deviation increase in neuroticism is associated with an 86 percent decrease in the probability of being accommodated. On the other hand, extraversion is positively correlated with employer accommodation, with a standard deviation increase in extraversion nearly doubling the likelihood of accommodation. Andreoni (1998) demonstrates that these patterns (high extraversion, low agreeableness/neuroticism) are positively correlated with dominating and 
negatively correlated with avoiding conflict management styles. ${ }^{13}$ Individuals with dominating styles tend to be aggressive in attaining their goals, and individuals with avoiding styles (who are unlikely to be accommodated) often fail to communicate their needs. Finally, individuals who measure high in perceiving constraints (i.e., limits on their sense of control) are more likely to be accommodated. A standard deviation increase in the perceived constraints measure is associated with a 53 percent increase in the probability of being accommodated.

Interestingly, traits that are positively correlated with employer accommodation tend to be negatively correlated with one another in the population. For example, extraversion is negatively correlated with perceived constraints ( $\mathrm{r}=-0.33$; see Table A2). Similarly, lack of neuroticism is strongly negatively correlated with perceived constraints ( $\mathrm{r}=-0.54)$, and lack of agreeableness is strongly negatively correlated with extraversion ( $\mathrm{r}=0.54)$. As a result, these individual factors tend to offset one another so that it takes an unusual kind of personality to receive accommodation.

Finally, columns 4 and 5 of Table 6 investigate the relationship between personality measures and labor force attachment using healthy HRS respondents who completed the psychosocial questionnaire. We find no evidence that any of the personality measures are correlated with work decisions. (Only one personality measure, neuroticism, is significantly associated with work, and the estimated coefficient is small and only marginally significant $(p<0.10)$.) Therefore, we conclude that we are unlikely to suffer from omitted variable bias if we exclude personality measures as control variables in regressions of labor supply outcomes on employer accommodation, so we can use our full sample of newly disabled older workers in our analysis of the causal effects of employer accommodation below.

\footnotetext{
${ }^{13}$ The other conflict management styles identified by Andreoni are: integrating, obliging and compromising.
} 


\section{Effect of Employer Accommodation on Labor Force Exit and Disability Insurance Claiming}

We now turn to estimating the causal effect of employer accommodation on the labor supply of newly disabled older workers. In the previous section we established that, conditional on observable characteristics such as education, race and job tenure, employer accommodation is unlikely to be correlated with unobservable factors that independently affect labor supply. Therefore OLS and propensity score methods are likely to yield unbiased estimates of the causal effects of employer accommodation. Table A3 presents the results of the unconfoundedness test suggested by Imbens (2014), demonstrating that lagged labor supply outcomes are uncorrelated with accommodation status, consistent with the conditional independence assumption. Figure 1 shows the distribution of propensity scores estimated from the regression reported in column 2 of Table 5, by accommodation status. Finally, Table A4 illustrates the balance between accommodated and non-accommodated respondents for selected characteristics, unweighted and reweighted using the propensity scores. As expected the reweighting reduces the difference between the treated and control groups.

Table 7 presents estimates of the effects of employer accommodation on various labor supply outcomes using both OLS and propensity score reweighting. In all cases the two methods yield similar estimates, suggesting that a model specification with a simple dummy variable for treatment is adequate in this setting. We find that employer accommodation increases the probability that an individual is working in the wave immediately after onset by more than 17 percentage points—a 40 percent increase over the baseline labor force participation rate of 45 percent. This difference reduces to a statistically insignificant 5-6 percentage points (12 percent) two years later, up to four years after disability onset, suggesting that employer accommodation 
may only temporarily stave off labor force exit after disability onset. Similarly, we do not find a significant effect of employer accommodation on applying for or receiving disability insurance within four years of disability onset.

Finally, in Table 8 we explore the sensitivity of our estimates to differences in specification, sample and estimation technique. Each row presents the estimated effect(s) of employer accommodation on the probability of working in the first wave following disability onset, defined as the first wave the respondent reports that his health limits his ability to work in some way. The first row reproduces the OLS estimate of the effect of any accommodation on work using the main sample of newly disabled workers who had been working at least two years when they first reported a work disability between 1994 and 2010. First, we examine how type of accommodation affects labor supply by including additional indicator variables for one of four dimensions of accommodation: time, work change, equipment/assistance or "other” (row 2; see Section 2 for definitions of these groups). For the most part, the type of accommodation does not have a strong impact on continuing to work beyond the provision of any accommodation, with the exception of work change accommodations which include changing the job to something the employee can do and helping the employee learn new skills. Employees who receive a work change accommodation are 28 percentage points (63 percent) more likely to work in the wave immediately following onset than employees who receive no accommodation at all, suggesting this is a particularly effective form of accommodation.

The next two rows (3-4) explore the sensitivity of the estimate to different sample restrictions. Recall that, prior to 1998, the HRS did not ask newly disabled respondents about their employment if they reported that their disability first began to bother them earlier than the previous wave. Row 3 restricts the sample to onsets first reported in the 1998 wave, which 
included full employment information for all respondents, even those reporting long standing health problems as the cause of their new disability. Because the sample is comprised of more individuals with long standing health problems, it is not surprising that the estimated effect of employer accommodation is somewhat smaller, 14.5 percentage points compared with 17.2 for the main sample. Similarly, row 4 includes onsets first reported in all years 1994-2010 but excludes those who report the impairment first began to bother them more than two years ago. In this case, the estimated effect of employer accommodation is somewhat higher, 20.7 percentage points, but still in the ballpark of the main estimate.

The last four rows explore sensitivity to different propensity score methods. Row 5 reports the results of a control function estimator which includes a polynomial function of the propensity score as a control variable proxying for potential selection bias (Heckman and Navarro-Lozano, 2004). The estimate of the control function itself is statistically insignificant (not shown) and the estimated effect of employer accommodation on work is well within the 95 percent confidence interval of the baseline estimate. The next three rows explore different propensity score matching techniques: radius matching, nearest neighbor matching and block matching (Imbens, 2014). To implement these techniques we first trim the propensity scores by throwing out the extreme values so that only propensity scores between 0.1 and 0.9 are used (Crump, Hotz, Imbens and Mitnik, 2008). After removing the outliers, we re-estimate the propensity scores and match with replacement using the re-estimated propensity scores. Radius and block matching produce similar results to our baseline estimates while nearest neighbor matching produces a slightly lower estimate of 14.6 percentage points (but still statistically indistinguishable from our main estimate). Taken together, these results suggest that our estimates are quite robust to different sample definitions and estimation methods. 


\section{Conclusion}

In this paper we use longitudinal data on newly disabled workers from the Health and Retirement Study to provide new evidence on what factors determine accommodation of newly disabled workers, as well as the short- and long-term effects of employer accommodation on employment and SSDI claiming behavior. We find that employee characteristics—most notably personality traits-largely determine which workers are accommodated following disability onset, suggesting that employees rather than employers bear the burden of communicating and asserting their needs. Workers who are accommodated by their employers are 40 percent more likely to work in the survey wave immediately following disability onset. However, this difference drops to a statistically insignificant 5 percent by the next survey wave (two years later), and we find no evidence that employer accommodation affects SSDI claiming behavior.

Our findings suggest that policies targeting the disclosure environment for disabled workers may be more effective in increasing accommodation rates than policies that target the employer side of the accommodation equation alone. If accommodation rates can be increased, many more workers would remain in the labor force, at least temporarily, but encouraging employer accommodation of disabilities is unlikely to affect the growing number of SSDI beneficiaries. 


\section{References}

Antonioni, David (1998). "Relationship Between the Big Five Personality Factors and Conflict Management Styles.” International Journal of Conflict Management 9 no. 4: 336-354.

Autor, David H. and Mark Duggan (2006). "The Growth in the Social Security Disability Rolls: A Fiscal Crisis Unfolding.” Journal of Economic Perspectives 20 no. 3: 71-96.

Autor, David H. and Mark Duggan (2010). "Supporting Work: A Proposal for Modernizing the U.S. Disability Insurance System.” Center for American Progress and The Hamilton Project, December 2010.

Autor, David H., Nicole Maestas, Kathleen J. Mullen and Alexander Strand (2011). “Does Delay Cause Decay? The Effect of Administrative Decision Time on the Labor Force Participation and Earnings of Disability Applicants.” MRRC Working Paper 2011-258.

Billstedt, E., Skoog, I., Duberstein, P., Marlow, T., Hällström, T., André, M. \& Waern, M. (2014). “A 37-year prospective study of neuroticism and extraversion in women followed from mid-life to late life.” Acta Psychiatrica Scandinavica, 129(1), 35-43.

Board of Trustees, Federal Old-Age and Survivors Insurance and Federal Disability Insurance Trust Funds (2013). "The 2013 Annual Report of the Board of Trustees of the Federal Old-Age and Survivors Insurance and Federal Disability Insurance Trust Funds.” Accessed on 12/17/13 at http://www.socialsecurity.gov/OACT/TR/2013/tr2013.pdf.

Bronchetti, Erin Todd and Melissa McInerney (forthcoming). "What Determines Employer Accommodation of Injured Workers? The Influence of Employer Workers' Compensation Costs, State Policies, and Case-Specific Characteristics.” Industrial and Labor Relations Review, forthcoming.

Bruyere, Susanne M. (2000). "Disability Employment Policies and Practices in Private and Federal Sector Organizations.” Ithaca, NY: Cornell University, School of Industrial and Labor Relations Extension Division, Program on Employment and Disability.

Bureau of Labor Statistics (2013). "Persons with a Disability: Barriers to Employment, Types of Assistance, and Other Labor-Related Issues-May 2012,” USDL-13-0729. Accessed on 3/31/14 at http://www.bls.gov/news.release/pdf/dissup.pdf.

Burkhauser, Richard V., J.S. Butler, and Yang Woo Kim (1995). "The Importance of Employer Accommodation on the Job Duration of Workeres with Disabilites: A Hazard Model Approach." Labour Economics 2 (1995): 109-30.

Burkhauser, Richard V., J. S. Butler, Yang-Woo Kim, and Robert R. Weathers (1999). "The Importance of Accommodation on the Timing of Disability Insurance Applications: Results from the Survey of Disability and Work and the Health and Retirement Study." The Journal of Human Resources 34, no. 3: 589-611.

Burkhauser, Richard V., and Mary Daly (2011). The Declining Work and Welfare of People with Disabilities. Washington, D.C.: The AEI Press.

Burkhauser, Richard V., Mary C. Daly and Philip R. de Jong (2008). "Curing the Dutch Disease: Lessons for United States Disability Policy.” MRRC Working Paper 2008-188.

Burkhauser, Richard V., Andrew J. Houtenville, and Jennifer Tennant (2012). "Capturing the Elusive Working-Age Population with Disabilities: Reconciling Conflicting Social Success Estimates from the Current Population Survey and American Community Survey.” Journal of Disability Policy Studies 24 no. 4: 195-205.

Burkhauser, Richard V., Maximilian D. Schmeiser, and Robert R. Weathers II (2012). "The Importance of Anti-Discrimination and Workers' Compensation Laws on the Provision 
of Workplace Accommodations Following the Onset of a Disability." Industrial and Labor Relations Review 65, no. 1: 161-80.

Campoleti, Michele (2005). "How Accommodations Affect the Duration of Post-Injury Employment Spells." Journal of Labor Research 26, no. 3: 485-99.

Charles, Kerwin Kofi (2005). "The Extent and Effect of Employer Compliance with the Accommodations Mandates of the Americans with Disabilities Act." Journal of Disability Policy Studies, 15(2), pp. 86-96.

Cobb-Clark, Deborah A., and Stefanie Schurer. (2012) "The stability of big-five personality traits." Economics Letters 115.1: 11-15.

Costa, P. T., Herbst, J. H., McCrae, R. R., \& Siegler, I. C. (2000). "Personality at midlife: Stability, intrinsic maturation, and response to life events.” Assessment, 7(4), 365-378.

Daly, Mary C., and John Bound (1996). "Worker Adaptation and Employer Accommodation Following the Onset of a Health Impairment." Journal of Gerontology: Social Sciences 51B, no. 2: 53-60.

Dehejia, Rajeev H., and Sadek Wahba (1999). "Causal Effects in Nonexperimental Studies: Reevaluating the Evaluation of Training Programs.” Journal of the American Statistical Association 94: 1053-1062.

DiNardo, John, Nicole M. Fortin, and Thomas Lemieux (1996). "Labor Market Institutions and the Distribution of Wages, 1973-1992: A Semiparametric Approach," Econometrica 64: 1001-1044.

Heckman, James J., and Salvador Navarro-Lozano (2004). "Using matching, instrumental variables and control functions to estimate economic choice models." Review of Economics and Statistics 86 no. 1: 30-57.

Hirano, Keisuke, Guido W. Imbens, and Geert Ridder (2003). "Efficient estimation of average treatment effects using the estimated propensity score." Econometrica 71.4: 1161-1189.

Høgelund, Jan and Anders Holm (2014). "Worker adaptation and workplace accommodations after the onset of an illness." IZA Journal of Labor Policy, 3:17.

Imbens, Guido (2014). "Matching Methods in Practice: Three Examples." NBER Working Paper No. 19959.

Leibman, Jeffrey B., and Jack A. Smalligan (2013). “An Evidence-Based Path to Disability Insurance Reform.” The Hamilton Project, Brookings Institution.

Specht, Jule, Boris Egloff, and Stefan C. Schmukle (2011). "Stability and change of personality across the life course: the impact of age and major life events on mean-level and rankorder stability of the Big Five." Journal of personality and social psychology 101.4: 862.

Race, Paul A., and Seth M. Dornier (2009). "ADA Amendments Act of 2008: The Effect on Employers and Educators.” Willamette Law Review 46: 357-406.

Von Schrader, Sarah, Valerie Malzer, and Susanne Bruyere (2013). "Perspectives on Disability Disclosure: The Importance of Employer Practices and Workplace Climate.” Employment Responsibilities and Rights Journal: 1-19.

Weber, Lauren. "Are You Disabled? Your Boss Needs to Know. New Regulations Require Federal Contractors to Ask Employees if They Have a Disability.” The Wall Street Journal, March 18, 2014. 
Figure 1. Distribution of Propensity Score by Accommodation Status

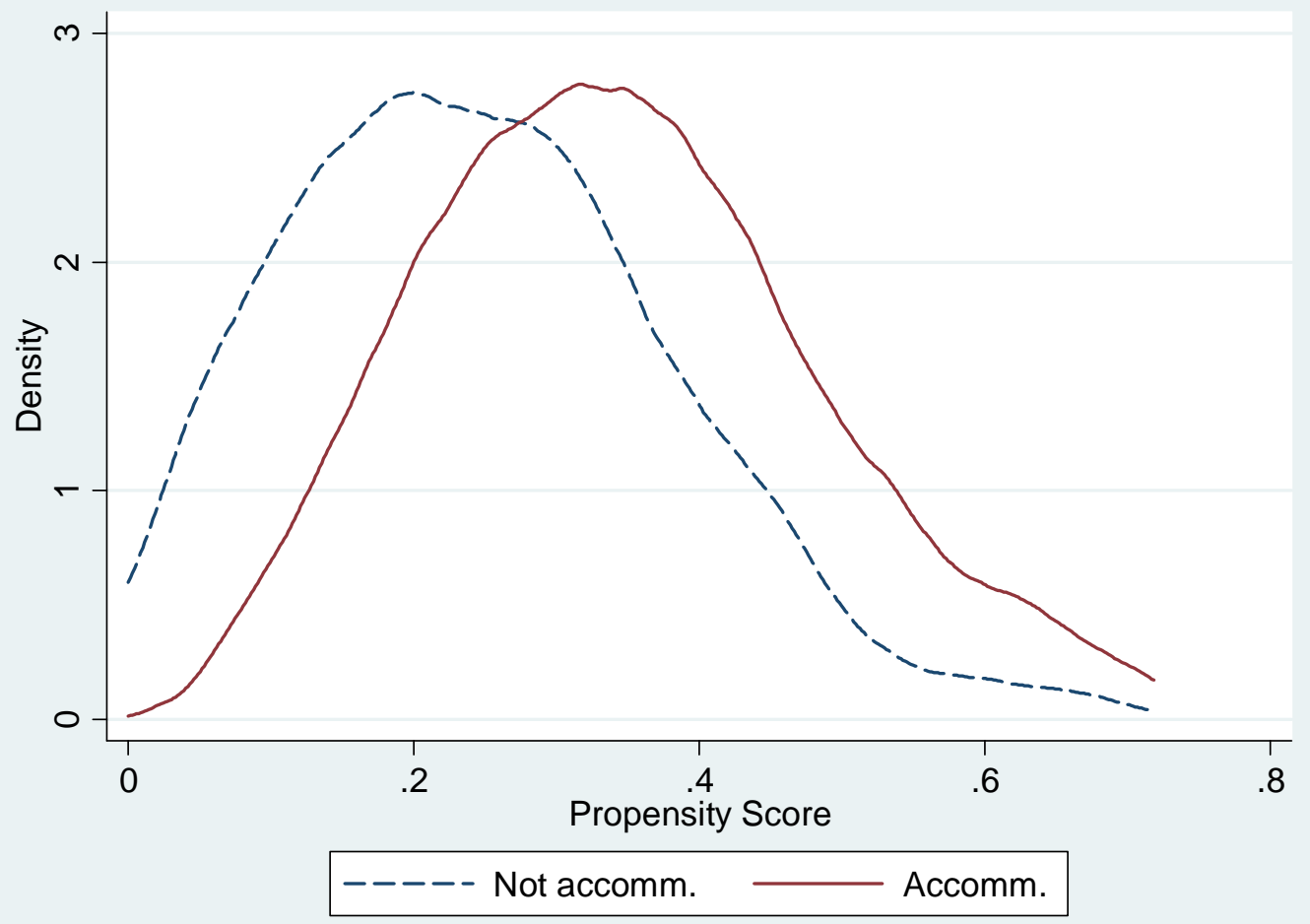




\begin{tabular}{lrr}
\hline \hline Sample & \multicolumn{2}{c}{$\begin{array}{c}\text { \% of } \\
\text { previous }\end{array}$} \\
\hline 1. HRS respondents entering panel without work disability & 15,906 \\
2. New disability onsets, age $<65$ & 3,144 & $20 \%$ \\
3. Employment at onset non-missing* & 2,279 & $72 \%$ \\
4. Employed at onset & 1,674 & $73 \%$ \\
$\quad$ Excluded responses to accommodation question & & \\
5. Self-employed & 1,640 & $98 \%$ \\
6. Left immediately & 1,558 & $95 \%$ \\
7. No help needed** & 1,453 & $93 \%$ \\
8. DK/RF/missing & 1,276 & $88 \%$ \\
9. Observed in wave prior to onset & 1,175 & $92 \%$ \\
10. Key covariates non-missing & 1,164 & $99 \%$ \\
11. Working in wave prior to onset & 972 & $84 \%$ \\
\hline \hline
\end{tabular}

Notes:

* Before 1998 this question was not asked if reported onset occurred prior to last interview. See text for details.

** Response added in 1998. 
Table 2. Summary Statistics

\begin{tabular}{|c|c|c|c|}
\hline Variable & Overall & Accomm. & $\begin{array}{c}\text { Not } \\
\text { Accomm. }\end{array}$ \\
\hline $\begin{array}{l}\text { \% received any accommodation } \\
\text { any time accommodation } \\
\text { any equipment/assistance } \\
\text { any work change accomm. } \\
\text { other accommodation }\end{array}$ & $26 \%$ & $\begin{array}{r}100 \% \\
55 \% \\
48 \% \\
37 \% \\
22 \%\end{array}$ & $0 \%$ \\
\hline \multicolumn{4}{|l|}{$\underline{\text { Demographic characteristics at onset }}$} \\
\hline Age & $\begin{array}{l}58.5 \\
(3.7)\end{array}$ & $\begin{array}{l}58.5 \\
(3.7)\end{array}$ & $\begin{array}{r}58.5 \\
(3.8)\end{array}$ \\
\hline Education (in years) & $\begin{array}{l}12.1 \\
(3.1)\end{array}$ & $\begin{array}{l}12.7 \\
(2.7)\end{array}$ & $\begin{array}{l}11.9 \text { *** } \\
(3.2)\end{array}$ \\
\hline Female & $59 \%$ & $56 \%$ & $60 \%$ \\
\hline Black & $20 \%$ & $16 \%$ & $21 \% *$ \\
\hline Married & $29 \%$ & $29 \%$ & $29 \%$ \\
\hline Wealth & $\begin{array}{r}227,290 \\
(472,852)\end{array}$ & $\begin{array}{r}218,275 \\
(366,625)\end{array}$ & $\begin{array}{r}230,425 \\
(504,725)\end{array}$ \\
\hline \multicolumn{4}{|l|}{$\underline{\text { Health in wave prior to onset }}$} \\
\hline Functional limitations index $(0-10)$ & $\begin{array}{c}1.38 \\
(1.46)\end{array}$ & $\begin{array}{c}1.35 \\
(1.43)\end{array}$ & $\begin{array}{c}1.39 \\
(1.47)\end{array}$ \\
\hline BMI & $\begin{array}{l}29.2 \\
(6.0)\end{array}$ & $\begin{array}{l}29.2 \\
(5.9)\end{array}$ & $\begin{array}{l}29.1 \\
(6.1)\end{array}$ \\
\hline Smoker & $28 \%$ & $26 \%$ & $28 \%$ \\
\hline Ever diagnosed diabetes & $16 \%$ & $14 \%$ & $17 \%$ \\
\hline Ever diagnosed blood pressure & $45 \%$ & $45 \%$ & $46 \%$ \\
\hline Ever diagnosed psychological problems & $14 \%$ & $17 \%$ & $13 \%$ \\
\hline Ever had back problems & $37 \%$ & $34 \%$ & $38 \%$ \\
\hline CESD score & $\begin{array}{c}1.7 \\
(2.1)\end{array}$ & $\begin{array}{c}1.6 \\
(2.0)\end{array}$ & $\begin{array}{c}1.8 \\
(2.1)\end{array}$ \\
\hline \multicolumn{4}{|l|}{ Characteristics of disability } \\
\hline Caused by nature of work & $34 \%$ & $36 \%$ & $33 \%$ \\
\hline Musculskeletal & $53 \%$ & $55 \%$ & $52 \%$ \\
\hline Circulatory & $12 \%$ & $11 \%$ & $12 \%$ \\
\hline Allergies & $6 \%$ & $4 \%$ & $6 \%$ \\
\hline Emotional & $2 \%$ & $1 \%$ & $2 \%$ \\
\hline Type not reported & $11 \%$ & $15 \%$ & $10 \%$ \\
\hline
\end{tabular}

Note: Accommodation types not mutually exclusive. See text for details. 
Table 2, continued. Summary Statistics

\begin{tabular}{|c|c|c|c|}
\hline Variable & Overall & Accomm. & $\begin{array}{c}\text { Not } \\
\text { Accomm. }\end{array}$ \\
\hline \multicolumn{4}{|l|}{ Job characteristics } \\
\hline Earnings (at onset) & $\begin{array}{c}32,102 \\
(33,297)\end{array}$ & $\begin{array}{c}35,280 \\
(29,847)\end{array}$ & $\begin{array}{l}30,982 * \\
(34,376)\end{array}$ \\
\hline Hours worked per week (at onset) & $\begin{array}{c}40.8 \\
(11.1)\end{array}$ & $\begin{array}{c}40.1 \\
(10.4)\end{array}$ & $\begin{array}{c}41.1 \\
(11.3)\end{array}$ \\
\hline Tenure in wave prior to onset & $\begin{array}{c}12.49 \\
(11.24)\end{array}$ & $\begin{array}{c}13.00 \\
(11.01)\end{array}$ & $\begin{array}{c}12.30 \\
(11.33)\end{array}$ \\
\hline Physical demands index (1-4, 1=most) & $\begin{array}{c}2.45 \\
(1.16)\end{array}$ & $\begin{array}{c}2.45 \\
(1.09)\end{array}$ & $\begin{array}{c}2.45 \\
(1.18)\end{array}$ \\
\hline Job stress index (1-4, 1=most) & $\begin{array}{c}2.15 \\
(0.85)\end{array}$ & $\begin{array}{c}2.16 \\
(0.83)\end{array}$ & $\begin{array}{l}2.14 \\
(0.85)\end{array}$ \\
\hline \multicolumn{4}{|l|}{ Employer characteristics } \\
\hline Offers long term disability insurance & $51 \%$ & $53 \%$ & $51 \%$ \\
\hline Accommodates older workers & $34 \%$ & $36 \%$ & $33 \%$ \\
\hline Allows reduced hours & $29 \%$ & $30 \%$ & $29 \%$ \\
\hline Less than 15 employees & $5 \%$ & $4 \%$ & $5 \%$ \\
\hline 15-24 employees & $2 \%$ & $3 \%$ & $2 \%$ \\
\hline 25-499 employees & $14 \%$ & $12 \%$ & $14 \%$ \\
\hline 500+ employees & $34 \%$ & $36 \%$ & $33 \%$ \\
\hline $\begin{array}{l}\text { Employee size not reported } \\
\text { Labor market outcomes }\end{array}$ & $46 \%$ & $45 \%$ & $46 \%$ \\
\hline Working in wave after onset & $45 \%$ & $58 \%$ & $40 \% * * *$ \\
\hline Working two waves after onset & $41 \%$ & $47 \%$ & $39 \% * *$ \\
\hline Applied for disability within two waves & $33 \%$ & $28 \%$ & $34 \% *$ \\
\hline Received disability within two waves & $22 \%$ & $20 \%$ & $23 \%$ \\
\hline No. obs. & 1,175 & 306 & 869 \\
\hline
\end{tabular}


Table 3. Healthy respondents' perceived probability of becoming disabled in next 10 years, by employer characteristic

\begin{tabular}{lcccc}
\hline \hline Employer characteristic & Yes & No & $\begin{array}{c}\text { Unadjusted } \\
\text { difference }\end{array}$ & $\begin{array}{c}\text { Adjusted } \\
\text { difference }\end{array}$ \\
\hline Offers long term disability insurance & 34.7 & 37.4 & $-2.7^{* * *}$ & -0.9 \\
& $(25.7)$ & $(26.7)$ & & \\
\hline Accommodates older workers & 35.1 & 36.1 & -1.0 & 1.3 \\
& $(25.7)$ & $(26.7)$ & & 1.1 \\
\hline Allows reduced hours & 36.1 & 36.0 & 0.1 & \\
\hline \hline
\end{tabular}

Note: Employer characteristic measured in first wave of employment by given employer. 


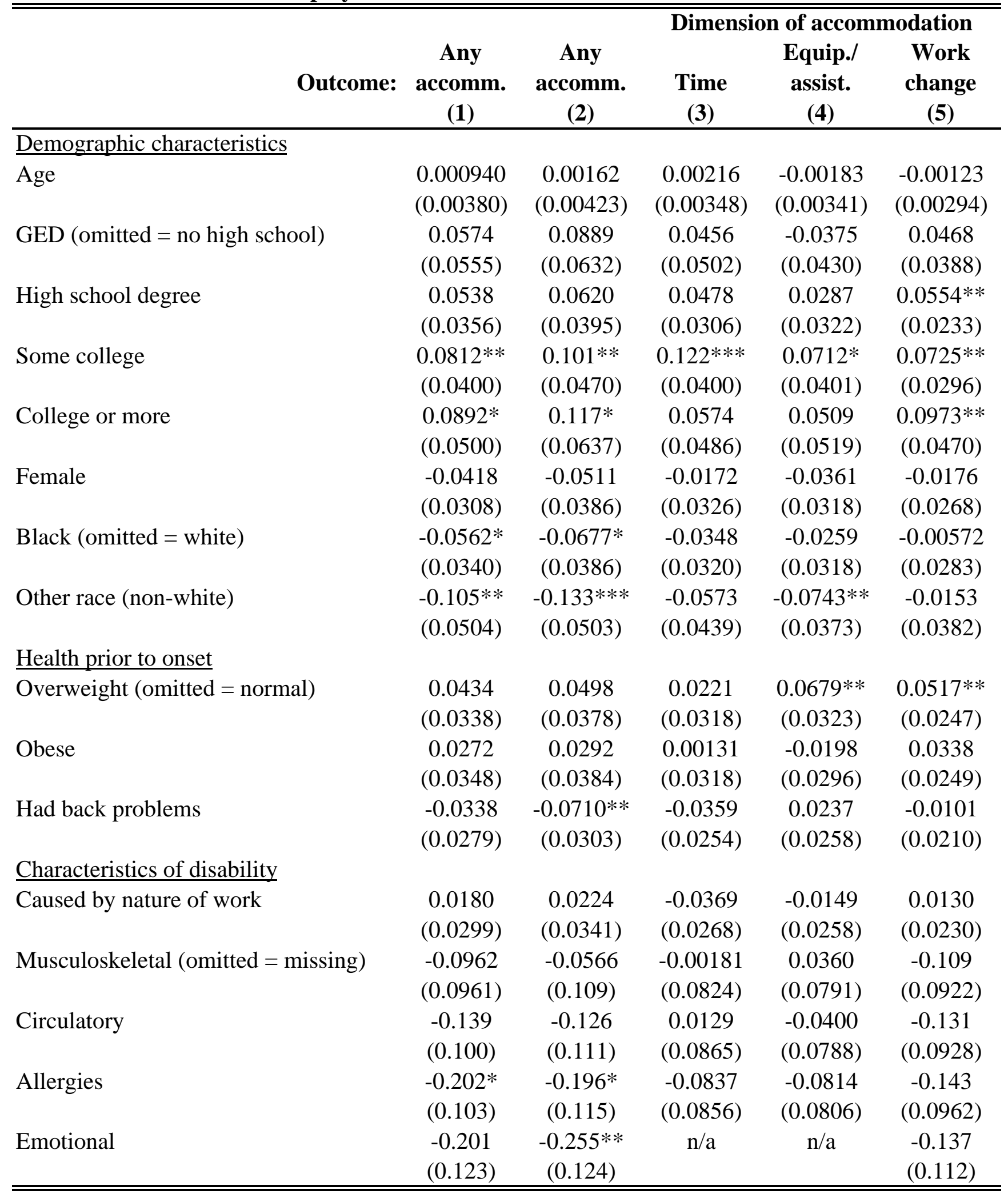




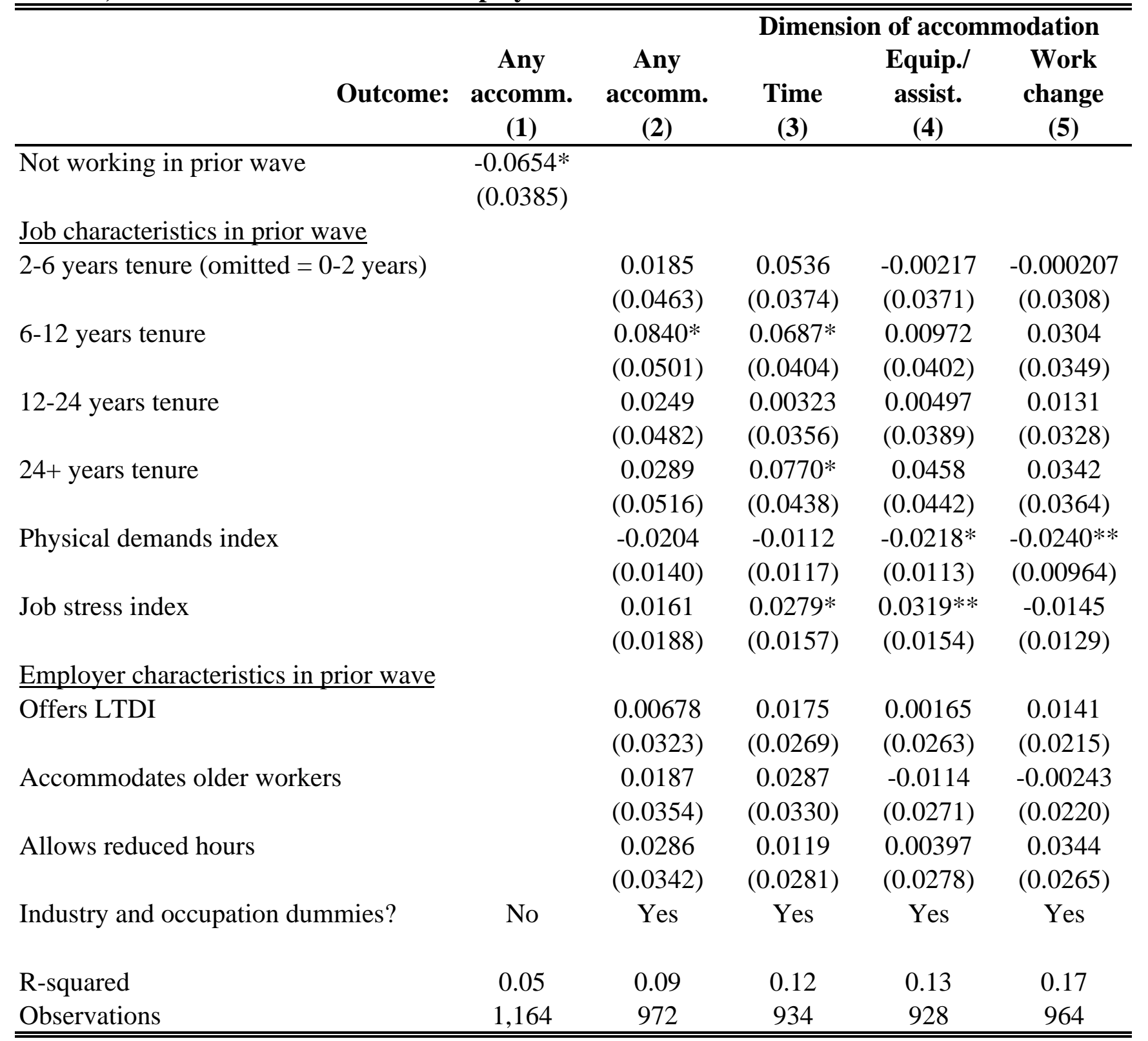

Standard errors in parentheses

*** $\mathrm{p}<0.01,{ }^{* *} \mathrm{p}<0.05,{ }^{*} \mathrm{p}<0.1$

Notes: Regressions include the following additional covariates: marital status, wealth deciles, earnings and hours worked at onset, terciles of functional limitations index prior to onset, smoking status, diagnosis dummies for diabetes, high blood pressure and psychological problems, CESD score, dummies for condition causing disability, dummies for firm size, missing variable dummies and year fixed effects. 
Table 5. Effect of Disability Onset on Personality Traits, 2010

\begin{tabular}{lccc}
\hline \hline & Lagged & Disability & \\
Dependent Variable & Trait & Onset & N \\
\hline Openness & $0.689^{* * *}$ & -0.007 & 3,920 \\
Conscientiousness & $(0.012)$ & $(0.016)$ & \\
& $0.683^{* * *}$ & $-0.028^{*}$ & 3,943 \\
Extraversion & $(0.013)$ & $(0.015)$ & \\
& $0.719^{* * *}$ & $-0.047^{* * *}$ & 3,952 \\
Agreeableness & $(0.012)$ & $(0.016)$ & \\
& $0.654^{* * *}$ & -0.008 & 3,958 \\
Neuroticism & $(0.013)$ & $(0.015)$ & \\
& $0.629^{* * *}$ & 0.028 & 3,951 \\
Personal mastery & $(0.012)$ & $(0.019)$ & \\
& $0.401^{* * *}$ & $-0.117^{* * *}$ & 3,982 \\
Perceived constraints & $(0.015)$ & $(0.040)$ & \\
& $0.523^{* * *}$ & $0.119^{* * *}$ & 3,976 \\
\hline \hline
\end{tabular}

$\overline{\text { Note: Sample includes all HRS respondents with personality measures }}$ in both 2006 and 2010. Standard errors in parentheses. ${ }^{* * *} \mathrm{p}<0.01$, ** $\mathrm{p}<0.05, * \mathrm{p}<0.1$. 
Table 6. Effect of Personality Measures on Accommodation and Work

\begin{tabular}{lccccc}
\hline \hline & Outcome: & \multicolumn{3}{c}{ Any Accommodation } & \multicolumn{2}{c}{ Work } \\
\hline & $\mathbf{( 1 )}$ & $\mathbf{( 2 )}$ & $\mathbf{( 3 )}$ & $\mathbf{( 4 )}$ & $\mathbf{( 5 )}$ \\
\hline Openness & 0.113 & 0.008 & -0.105 & 0.024 & 0.005 \\
& $(0.093)$ & $(0.107)$ & $(0.102)$ & $(0.0148)$ & $(0.0151)$ \\
Conscientiousness & -0.0627 & -0.021 & -0.071 & 0.021 & 0.013 \\
& $(0.094)$ & $(0.116)$ & $(0.108)$ & $(0.0169)$ & $(0.017)$ \\
Extraversion & 0.155 & $0.240^{* *}$ & $0.414^{* * *}$ & 0.001 & 0.012 \\
& $(0.099)$ & $(0.113)$ & $(0.102)$ & $(0.0152)$ & $(0.0152)$ \\
Agreeableness & -0.147 & $-0.191^{*}$ & $-0.367^{* * *}$ & -0.0167 & -0.002 \\
& $(0.099)$ & $(0.111)$ & $(0.123)$ & $(0.0169)$ & $(0.0174)$ \\
Neuroticism & $-0.156^{* *}$ & $-0.199^{* *}$ & $-0.321^{* * *}$ & -0.0160 & $-0.0195^{*}$ \\
& $(0.0775)$ & $(0.087)$ & $(0.081)$ & $(0.012)$ & $(0.0116)$ \\
Personal mastery & 0.015 & 0.017 & 0.009 & -0.010 & -0.010 \\
& $(0.0501)$ & $(0.0567)$ & $(0.051)$ & $(0.007)$ & $(0.007)$ \\
Perceived constraints & $0.091^{*}$ & $0.113^{* *}$ & $0.125^{* *}$ & -0.0094 & -0.0034 \\
& $(0.050)$ & $(0.053)$ & $(0.050)$ & $(0.007)$ & $(0.007)$ \\
Includes controls? & No & No & Yes & No & Yes \\
Disabled sample? & Yes & Yes & Yes & No & No \\
Restricted to working prior wave & No & Yes & Yes & Yes & Yes \\
R-squared & 0.07 & 0.09 & 0.35 & 0.01 & 0.04 \\
Observations & 115 & 90 & 90 & 3,258 & 3,257 \\
\hline \hline
\end{tabular}

Standard errors in parentheses

*** $\mathrm{p}<0.01, * * \mathrm{p}<0.05, * \mathrm{p}<0.1$ 
Table 6. Effect of Personality Measures on Accommodation and Work

\begin{tabular}{lccccc}
\hline \hline & Outcome: & \multicolumn{3}{c}{ Any Accommodation } & \multicolumn{2}{c}{ Work } \\
\hline & $\mathbf{( 1 )}$ & $\mathbf{( 2 )}$ & $\mathbf{( 3 )}$ & $\mathbf{( 4 )}$ & $\mathbf{( 5 )}$ \\
\hline Openness & 0.113 & 0.008 & -0.105 & 0.024 & 0.005 \\
& $(0.093)$ & $(0.107)$ & $(0.102)$ & $(0.0148)$ & $(0.0151)$ \\
Conscientiousness & -0.0627 & -0.021 & -0.071 & 0.021 & 0.013 \\
& $(0.094)$ & $(0.116)$ & $(0.108)$ & $(0.0169)$ & $(0.017)$ \\
Extraversion & 0.155 & $0.240^{* *}$ & $0.414^{* * *}$ & 0.001 & 0.012 \\
& $(0.099)$ & $(0.113)$ & $(0.102)$ & $(0.0152)$ & $(0.0152)$ \\
Agreeableness & -0.147 & $-0.191^{*}$ & $-0.367^{* * *}$ & -0.0167 & -0.002 \\
& $(0.099)$ & $(0.111)$ & $(0.123)$ & $(0.0169)$ & $(0.0174)$ \\
Neuroticism & $-0.156^{* *}$ & $-0.199^{* *}$ & $-0.321^{* * *}$ & -0.0160 & $-0.0195^{*}$ \\
& $(0.0775)$ & $(0.087)$ & $(0.081)$ & $(0.012)$ & $(0.0116)$ \\
Personal mastery & 0.015 & 0.017 & 0.009 & -0.010 & -0.010 \\
& $(0.0501)$ & $(0.0567)$ & $(0.051)$ & $(0.007)$ & $(0.007)$ \\
Perceived constraints & $0.091^{*}$ & $0.113^{* *}$ & $0.125^{* *}$ & -0.0094 & -0.0034 \\
& $(0.050)$ & $(0.053)$ & $(0.050)$ & $(0.007)$ & $(0.007)$ \\
Includes controls? & No & No & Yes & No & Yes \\
Disabled sample? & Yes & Yes & Yes & No & No \\
Restricted to working prior wave & No & Yes & Yes & Yes & Yes \\
R-squared & 0.07 & 0.09 & 0.35 & 0.01 & 0.04 \\
Observations & 115 & 90 & 90 & 3,258 & 3,257 \\
\hline \hline
\end{tabular}

Standard errors in parentheses

*** $\mathrm{p}<0.01, * * \mathrm{p}<0.05, * \mathrm{p}<0.1$ 
Table 7. Effect of Employer Accommodation on Labor Supply

\begin{tabular}{lccr}
\hline \hline Dependent Variable & OLS & RW(p) & $\mathbf{~ N}$ \\
\hline Working in immediate post-onset wave & $0.172^{* * *}$ & $0.176^{* * *}$ & 972 \\
Working two waves after onset & $(.033)$ & $(.036)$ & \\
& 0.045 & 0.056 & 795 \\
Applied for disability insurance w/in 4 years & $(.037)$ & $(.043)$ & \\
& -0.037 & -0.046 & 812 \\
Received disability insurance w/in 4 years & $(.035)$ & $(.040)$ & \\
& 0.017 & 0.012 & 808 \\
\hline \hline
\end{tabular}

Standard errors in parentheses

$* * * \mathrm{p}<0.01, * * \mathrm{p}<0.05, * \mathrm{p}<0.1$ 
Table 8. Sensitivity and Robustness Checks

\begin{tabular}{lccccc}
\hline \hline Specification/Estimator & $\begin{array}{c}\text { Any } \\
\text { Accomm. }\end{array}$ & Time & $\begin{array}{c}\text { Equip./ } \\
\text { Assist. }\end{array}$ & $\begin{array}{c}\text { Work } \\
\text { Change }\end{array}$ & Other \\
\hline 1. Baseline (OLS) & $0.172^{* * *}$ & & & & \\
& $(.033)$ & & & & \\
2. Include type of accommodation & $0.150^{* *}$ & -0.00311 & -0.0130 & $0.133^{* *}$ & -0.0503 \\
& $(0.0668)$ & $(0.0597)$ & $(0.0591)$ & $(0.0601)$ & $(0.0604)$ \\
3. Restrict to onsets occuring after 1996 & $0.145^{* * *}$ & & & & \\
& $(.041)$ & & & \\
4. Restrict to onsets reported within 2 years & $0.207^{* * *}$ & & & \\
& $(.049)$ & & & \\
5. Control function & $0.186^{* * *}$ & & & \\
6. Radius matching & $(0.040)$ & & & \\
& $0.18^{* * *}$ & & & \\
7. Nearest neighbor matching & $(0.037)$ & & & \\
& $0.146^{* * *}$ & & & \\
8. Block matching & $(0.054)$ & & & \\
& $0.180^{* * *}$ & & & \\
\hline \hline
\end{tabular}

Standard errors in parentheses

$* * * \mathrm{p}<0.01, * * \mathrm{p}<0.05,{ }^{*} \mathrm{p}<0.1$ 
Table A1. Types of Accommodation

\begin{tabular}{lr}
\hline \hline Accommodation type & \% \\
\hline Time: & 37.3 \\
Allow more breaks or rest periods & 37.2 \\
Allow arrival or departure change & 27.9 \\
Shorten work day & 36.6 \\
\hline Equipment/ Assistance: & 15.1 \\
Get someone to help you & 4.3 \\
Get special equipment for job & 33.2 \\
Arrange special transportation & 12.2 \\
\hline Work change: & 21.9 \\
\hline Change the job to something they could do \\
Help learn new skills
\end{tabular}

Note: Accommodation types are are not mutually exclusive categories. 


\begin{tabular}{|c|c|c|c|c|c|c|c|c|c|}
\hline Measure & Mean & Std. dev. & $\begin{array}{l}\mathscr{e} \\
\stackrel{E}{E} \\
\tilde{\Xi}\end{array}$ & 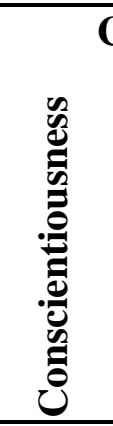 & 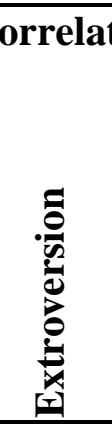 & 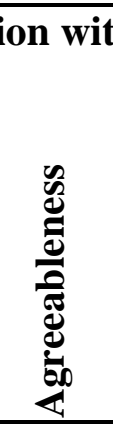 & 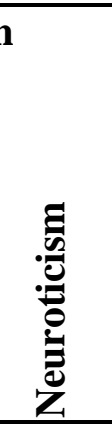 & 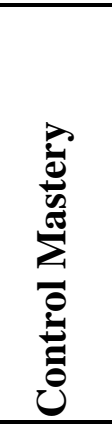 & 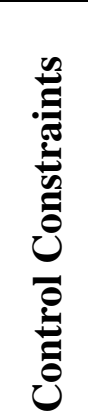 \\
\hline \multicolumn{10}{|l|}{ Personality (1-4) } \\
\hline Openness & 2.9 & 0.5 & 1.00 & & & & & & \\
\hline Conscientiousness & 3.3 & 0.5 & 0.42 & 1.00 & & & & & \\
\hline Extroversion & 3.0 & 0.6 & 0.53 & 0.34 & 1.00 & & & & \\
\hline Agreeableness & 3.5 & 0.5 & 0.37 & 0.38 & 0.54 & 1.00 & & & \\
\hline Neuroticism & 2.3 & 0.7 & -0.25 & -0.26 & -0.20 & -0.15 & 1.00 & & \\
\hline \multicolumn{10}{|l|}{ Sense of Control (1-6) } \\
\hline Personal Mastery & 4.7 & 1.0 & 0.28 & 0.30 & 0.29 & 0.08 & -0.33 & 1.00 & \\
\hline Perceived Constraints & 2.2 & 1.1 & -0.30 & -0.15 & -0.33 & -0.16 & 0.54 & -0.49 & 1.00 \\
\hline No. obs. & 115 & & & & & & & & \\
\hline
\end{tabular}




\begin{tabular}{lccccc}
\hline \hline Lagged outcome & \multicolumn{3}{c}{ Not } \\
Accomm. & Accomm. & Diff. & p-value & N \\
\hline Working two waves prior to onset & $95.9 \%$ & $93.3 \%$ & $2.6 \%$ & 0.199 & 721 \\
Working three waves prior to onset & $92.8 \%$ & $93.0 \%$ & $-0.2 \%$ & 0.937 & 525 \\
\hline \hline
\end{tabular}

Table A4. Covariate balance, unweighted and weighted by probit p-scores

\begin{tabular}{lcccccc}
\hline \hline \multirow{2}{*}{ Variable } & \multicolumn{3}{c}{ Unweighted } & \multicolumn{3}{c}{ Weighted (probit p-scores) } \\
\cline { 2 - 7 } & Difference & S.E. & t-stat & Difference & S.E. & t-stat \\
\hline Age & 0.03 & 0.27 & 0.12 & 0.13 & 0.29 & 0.45 \\
Education (in years) & 0.77 & 0.22 & 3.56 & 0.18 & 0.19 & 0.91 \\
Female & -0.04 & 0.04 & -1.04 & 0.01 & 0.04 & 0.16 \\
Black & -0.05 & 0.03 & -1.81 & 0.00 & 0.03 & -0.02 \\
Job tenure & 0.70 & 0.81 & 0.86 & 0.04 & 0.85 & 0.05 \\
Earnings at onset & 2669 & 2186 & 1.22 & -698 & 2409 & -0.29 \\
\hline \hline
\end{tabular}

Note: Sample is 972 respondents working in wave prior to onset. 